\title{
AÇÕES CONTRA HOMOFOBIA EM PROJETOS DE FORMAÇÃO CONTINUADA DE EDUCADORES
}

Mary Neide Figueiró ${ }^{1}$

\section{ACTIONS AGAINST HOMOPHOBIA IN CONTINUED EDUCATION PROJECTS FOR EDUCATORS}

Resumo: $\mathrm{O}$ presente texto aborda a experiência em formação de educadores sexuais, na Universidade Estadual de Londrina (UEL) - PR, destacando-se o período de 2006 a 2007, no qual o projeto de extensão ampliou-se, unindose ao Programa Brasil Sem Homofobia (MEC/SECAD, de Brasília). Desta forma, Grupos de Estudos sobre Educação Sexual (GEES), desenvolvidos desde 1995, passaram a ser reforçados por outras açōes, quais sejam: assessoria aos profissionais já formados pelo GEES; realização de eventos sobre a temática, a fim de aprofundar o aprendizado e possibilitar a proximidade dos integrantes com homossexuais militantes e, ainda, sensibilizar outros para o combate à homofobia; realização de oficinas sobre diversidade sexual nas escolas; publicação e distribuição gratuita de livros sobre o tema. Inserida numa perspectiva de Educação Sexual emancipatória, a experiência tem sido uma clara demonstração do quanto o ensino sobre a sexualidade necessita estar vinculado a lutas sociais, entre essas, a luta contra a opressão, a discriminação e a violência.

Palavras-chave: Formação de educadores sexuais; homofobia; homossexualidade.

Abstract: This text deals with the experience in educating sexual educators, at the State University of Londrina (UEL) - PR, especially in the period from

Psicóloga e docente do Depto de Psicologia Social e Institucional da UEL. Mestre em Psicologia Escolar /USP e Doutora em Educação / UNESP. Especialista em Educação Sexual pela Sociedade Brasileira de Estudos em Sexualidade Humana - SBRASH. e-mail: figueiro@onda.com.br 
2006 to 2007 in which the community project was expanded, joining the Programa Brasil Sem Homofobia (Program Brazil Without Homophobia) (MEC/SECAD, from Brasília). In this way, Study Groups on Sexual Education (SGSE), developed since 1995, were strengthened by other actions, such as: assistance to professionals who had already taken part in the SGSEs; organization of events on the theme in order to deepen learning as well as to enable participants' proximity with homosexuals and also to touch others to struggle against homophobia; organization of workshops on sexual diversity in schools; publishing and free distribution of books on the theme. Inserted in an emancipatory Sexual Education perspective, the experience has been a clear demonstration of how the teaching about sexuality needs to be linked to social struggles, having among them the struggle against oppression, discrimination and violence.

Keywords: Education of sexual educators; homophobia; homosexuality.

\section{Introdução}

A maioria dos professores necessita de formação específica para atuar no ensino da sexualidade, porque os cursos universitários não asseguram, com sua grade curricular, uma formação que dê conta disto. Minha experiência e contato direto com esses profissionais têm mostrado que eles vêm enfrentando muitas situações ligadas à manifestação da sexualidade, as quais exigem conhecimentos e habilidades específicas. Eles percebem a lacuna existente em sua formação e têm consciência de que precisam de oportunidades para aprender a lidar com questôes do cotidiano escolar que têm relação direta, ou indireta, com a temática da sexualidade.

Preparar o educador sexual não é tarefa simples, e não depende, unicamente, da participação em cursos pontuais. Há várias condições que precisam ser asseguradas, tanto durante o seu processo formativo, quanto no período após sua formação, para que ele consiga colocar em prática, com eficácia, o que aprendeu.

Desde 1995, coordeno, na Universidade Estadual de Londrina (UEL), Grupos de Estudos sobre Educação Sexual (GEES), que visam preparar educadores dos vários níveis de ensino, para atuar na Educação Sexual de crianças, adolescentes, jovens, adultos e idosos. O GEES pauta-se num trabalho formativo, a longo prazo, com encontros semanais, de quatro horas, de maio a fim de novembro, perfazendo um total de 22 encontros durante o ano. Em cada edição, 
são abertos e desenvolvidos, no próprio campus universitário, quatro novos grupos, compostos, cada um, de 20 integrantes.

O Ministério da Educação abriu concorrência, em 2005, para financiar "Projetos Capacitação/Formação de Profissionais da Educação para a Cidadania e a Diversidade Sexual". A Universidade Estadual de Londrina foi contemplada, juntamente com mais uma universidade pública e 13 ONGs, dentre um conjunto de 95 projetos concorrentes. Assim sendo, o Projeto/ UEL, de extensão universitária, ao passar à sua oitava edição, em 2006, agregou-se ao Programa Brasil Sem Homofobia, com o apoio do Ministério da Educação (MEC) e da Secretaria de Educação Continuada, Alfabetização e Diversidade (SECAD). A partir daí, o projeto diversificou-se e ampliou as suas ações educativas, passando a denominar-se: "Formação de Profissionais para a Educação Sexual, o Combate à Homofobia e a Promoção da Cidadania Homossexual".

Homofobia é a aversão e/ou o medo que as pessoas preconceituosas sentem em relação aos gays, lésbicas, bissexuais, transgêneros e transexuais (GLBTT), tornando estes, vítimas de intolerância, de desprezo, de indiferença e, muito comumente, de agressão verbal e física.

Segundo o relatório elaborado pelo Grupo Gay da Bahia (ASSASSINATOS, 2005), foram mortos, no Brasil, 2.511 homossexuais, no período de 1980 a 2005, “[...] em sua maior parte, vítimas de crimes homofóbicos, onde o ódio da homossexualidade se manifesta através de requintes de crueldade [...]". O texto dá uma noção mais concreta desta incidência, ao afirmar que acontece "[...] um crime de ódio anti-homossexual a cada 3 dias. Dois por semana. Oito por mês. Uma média de 100 homicídios anuais. A partir de 2000 essa média vem aumentando: 125 crimes por ano, sendo que em 2004 atingiu o recorde: 158 homicídios".

O fator principal que impulsionou a busca da vinculação do Projeto/UEL ao Programa Brasil sem Homofobia foi a constatação de que o tema da diversidade sexual sempre foi recorrente nos GEES e um dos mais difíceis de se trabalhar. A cada novo grupo que se inicia, os integrantes expressam seu desconhecimento em relação ao tema da homossexualidade, seus medos, suas angústias e suas inseguranças. Frequentemente, e desde os primeiros encontros, costumam aparecer, em todo GEES, as dúvidas: como agir diante da presença de alunos homossexuais na escola; como e o que fazer diante da "suspeita" de alunos que possam ser (ou vir a ser) homossexuais; como responder a perguntas dos alunos, que estejam relacionadas ao tema homossexualidade; porque as pessoas se tornam homossexuais, e assim por diante. 
Acredito que

[...] a formação continuada de educadores necessita estar atrelada a todas as lutas sociais, em especial, àquelas voltadas para a construção da cidadania, eliminando toda forma de opressão, violência, discriminação e desigualdade. Só assim será possível concretizar uma educação escolar que contribua, efetivamente, para a realização e a felicidade das pessoas e para a transformação social. (FIQUEIRÓ, 2007, p. 6)

\section{Formação continuada de educadores}

O ensino, concebido como uma profissão, impõe a necessidade de envolvimento dos professores num processo contínuo de formação. Vistos não mais apenas como quem transmite informações aos seus alunos, mas também como profissionais que criam e constroem conhecimentos sobre o processo ensinoaprendizagem, os professores, em sua maioria, vêm sentindo e reconhecendo a importância de estarem envolvidos, constantemente, num processo de crescimento pessoal, cultural e profissional. Que elementos justificam a necessidade desse continuum na formação dos professores?

De acordo com Barbieri, Carvalho e Uhle (1995), a razão mais premente referese à própria natureza do fazer pedagógico. Ao invés de caracterizar-se como atividade puramente racional, tal qual uma técnica, é um tipo de fazer que se constitui como domínio da práxis, porque é histórico, incompleto e mutável. Assim, exige de cada educador um aprendizado constante. Por outro lado: "Se a educação só tem pleno sentido como educação para a auto-reflexão, é preciso que os que educam possam experimentar os limites e as possibilidades dessa modalidade educativa na própria pele" (PATTO, 1995, p.13).

Durante a formação inicial, o exercício da auto-reflexão, ou mais propriamente, da reflexão sobre a prática pedagógica, fica limitado. É após estar inserido na prática profissional, deparando-se com possibilidades e limites seus, dos seus alunos e do contexto educacional como um todo (em nível micro e macro institucional), que os professores poderão exercitar a reflexão.

Não se pode perder de vista, primeiramente, o significado da formação do educador, pois ela envolve tanto a inicial, quanto a continuada, sem, no entanto, restringir-se a estes momentos, uma vez que começa a acontecer antes mesmo da formação inicial e prossegue ao longo de todo o período da prática profissional. Durante os anos de vida anteriores ao ingresso no curso de formação inicial, a pessoa vai construindo suas representações sociais, seus significados do que seja a escola, o ensino, o papel do professor e o do aluno, e assim por 
diante. Portanto, as experiências de vida da pessoa, anteriores e posteriores à sua formação inicial contribuem para o processo de formação do educador. A pratica profissional, por sua vez, deve ser valorizada como o fio condutor central.

Partindo do que seja formação, é importante nos voltarmos para o conceito de formação continuada, em seu sentido estrito, pelo qual este trabalho se norteia. Formação continuada refere-se às propostas ou açōes, tais como cursos, estudos e reflexões voltados, em primeira instância, para aprimorar a prática profissional do professor. Diz respeito a todas as formas deliberadas e organizadas para este fim.

No entanto, para se constituir numa prática social transformadora, a formação continuada deve, segundo Alarcão (1998), contribuir para o desenvolvimento profissional do professor individualmente, para o coletivo dos professores em busca da identidade de seus saberes e para uma escola renovada. No dizer de Nóvoa (1997), a formação continuada deve produzir a vida do professor, a profissão do professor e a escola.

A efetividade desse tipo de formação depende de estar apoiada em vários pressupostos. O primeiro deles é que o professor seja considerado construtor, sujeito de sua própria maneira de ser e agir profissional; a sua experiência e a sua realidade de vida e de trabalho são vistas como elementos significativos no processo. $\mathrm{O}$ segundo pressuposto é que haja suporte para o professor, no sentido de apoio, desafios e estímulos durante o processo, e que o formador possa assumir o papel de facilitador e mobilizador da formação. O terceiro, é que é preciso considerar a escola como objeto de reflexão e como local de ação, ou seja, é preciso conceber o professor como um profissional que pensa, reflete e que também toma decisóes, experimenta, atua e avalia. $\mathrm{O}$ último pressuposto é a necessidade de compreender o professor como um profissional que também produz saberes em sua prática profissional e, não simplesmente como um técnico e um transmissor (ALARCÃO, 1998).

Uma característica fundamental da formação continuada é que precisa ter ligação com problemas que os professores enfrentam em sua sala de aula. Essa formação "[...] será tanto mais efetiva quanto maior for o envolvimento do próprio professor na busca de soluçōes para seus problemas" (CELANI, 1988, p.160).

A importância de partir de problemas que os professores estejam vivenciando é salientada por vários estudiosos, como Basso (1998), Feil (1985) e Kramer (1989), entre outros. 
A sexualidade é uma das questões que mais tem trazido dificuldades, problemas e desafios aos educadores, no seu trabalho cotidiano de ensinar. A manifestação da sexualidade dos alunos no espaço escolar ou, mais comumente, na sala de aula, está, de modo geral, exacerbada, tendo em vista a forma como a sociedade atual e os meios de comunicação, em especial, abordam-na. Temos observado forte instigação ao sexo, como também, um rompimento com os valores morais e sexuais há muito estabelecidos.

Giddens (1993), ao delinear e analisar as várias transformações pelas quais a sexualidade começou a passar nas proximidades do final do século XX, afirma que, muitos comportamentos, que antes eram vistos como desvios, hoje são tidos como possibilidade, o que se dá, também, com a vivência da homossexualidade. Penso que, por ser esta uma questão pouco compreendida e permeada de tabus, ao aparecer como possibilidade, também no espaço da escola, e ao mesmo tempo como problema - na visão dos que não a compreendem - acaba por ser um importante fator instigador da formação continuada dos profissionais da educação e da saúde.

\section{Ações contra homofobia}

[...] Viver sob o preconceito não é tarefa fácil e produz efeitos nocivos à saúde psíquica de qualquer pessoa discriminada.

(LULA RAMIRES, 2004)

A homofobia tem se manifestado com incidência significativa, na sociedade, em geral, e, inclusive, no espaço da escola, interferindo, negativamente, na dinâmica do processo educativo dos alunos. Muitos estudiosos denunciam a presença crescente e descontrolada da homofobia e comentam sobre as suas implicações pessoais e sociais. Entre eles, citam-se: Peres (2004, 2005), Mott (1997), Terto Jr. (1996).

Além de gerar violência, muitas vezes explícita, outras velada, para com alunos/ as homossexuais, a homofobia faz com que outros alunos, que conseguem esconder o fato de serem homossexuais, vivam na invisibilidade, conforme mostra, por exemplo, o estudo de Caetano (2005). Assim, estes alunos, devido ao medo do desprezo, da indiferença, dos maus tratos e até da violência, envolvem-se num silenciamento, "num controle rigoroso dos gestos e da voz, para não serem reconhecidos” (p. 7).

O Programa Brasil sem Homofobia (BRASIL, 2004), ao apontar para o alto índice de violência contra pessoas homossexuais, afirma que: 
[...] A violência letal contra homossexuais - e mais especificamente contra travestis e transgêneros - é, sem dúvida, uma das faces mais trágicas da discriminação por orientação sexual ou homofobia no Brasil. Tal violência tem sido denunciada com bastante veemência pelo movimento GLTB, por pesquisadores de diferentes universidades brasileiras e pelas organizações da sociedade civil, que têm procurado produzir dados de qualidade sobre esta situação. (BRASIL, 2004, p.16)

Uma pesquisa que teve o apoio da UNESCO, feita por Abramovay, Castro e Silva (2004), junto a quatorze capitais brasileiras, envolvendo estudantes do ensino fundamental, seus pais e professores, aponta que, entre 30 a $52,9 \%$ dos professores pesquisados afirmam conhecer o suficiente sobre homossexualidade. Avalio como baixo este nível, e creio que devemos considerar que, principalmente nesta temática, nem sempre a aquisição de conhecimento vem acompanhada de mudança de atitude, ou seja, de superação de preconceitos e tabus. No entanto, é animador o seguinte resultado encontrado nessa pesquisa:

[...] Vários professores afirmam que o preconceito deve ser combatido pela escola. Há também depoimentos que sugerem que a escola pode desconstruir a discriminação, tanto por ação planejada e intencional quanto por tratamento pró-inclusão, incentivando o respeito à diversidade e ressaltando nos alunos a auto-estima e qualidades como o esforço e o desempenho escolar. (ABRAMOVAY, CASTRO, SILVA, 2004, p. 304)

Entre as várias temáticas trabalhadas nos cursos de formação de educadores (FIGUEIRÓ, 2001, 2006), desenvolvidos no projeto da UEL, a homossexualidade pode ser considerada a mais complexa, por envolver um alto grau de atitudes resistentes a mudanças, requerendo, assim, um trabalho relativamente prolongado e reiterado. Acontece, porém, que muitos são os temas a serem estudados, o que compromete o estudo aprofundado deste assunto. Desse modo, quando o Projeto/UEL de formação de educadores sexuais passou a integrar-se ao Programa Brasil sem Homofobia, outras açōes foram propostas, para reforçar os estudos feitos sobre a homossexualidade, nos GEES, e se criar um espaço sólido para o estudo das implicações da homofobia e do papel da escola na superação da discriminação e da violência a gays, lésbicas, bissexuais, transgêneros e transexuais (GLBTT).

O conjunto das ações contra homofobia, proposto no Projeto/UEL: "Formação de Profissionais para a Educação Sexual, o Combate à Homofobia e a Promoção da Cidadania Homossexual", que está em andamento desde o início de 2006 (prosseguindo até o final de 2007), foi organizado em três vertentes:

a) A continuidade da realização dos Grupos de Estudos sobre Educação Sexual (GEES) 
b) A criação do Mutirão Orientador (M.O.): Assessoria aos profissionais já formados pelo GEES;

c) A realização de eventos sobre a temática Homossexualidade/diversidade sexual, na Universidade.

Considerando-se que, a partir de novembro de 2006, o MEC/SECAD reforçou seu apoio financeiro ao Projeto/UEL, duas outras vertentes de trabalho foram incorporadas no início de 2007:

a) A realização de oficinas, em escolas públicas, sobre a educação para o respeito à diversidade sexual, destinadas aos educadores.

b) A publicação de material de apoio didático aos educadores.

Antes de discorrer sobre cada uma destas ações, é necessário pontuar dois elementos, referentes ao projeto como um todo, que as embasam. $\mathrm{O}$ primeiro destes elementos diz respeito ao fato de que o projeto passou a ser de caráter interdisciplinar, pois, até então, era restrito ao departamento de Psicologia da UEL; assim, docentes e estudantes de outros departamentos/cursos passaram a fazer parte do mesmo; entre eles: Serviço Social, Ciências Sociais, Enfermagem e Biologia. O segundo destes elementos éo fato de que, com o apoio financeiro do MEC/SECAD, foi possível fazer contratação remunerada de quatro psicólogos com experiência em trabalhos de formação de educadores sexuais.

Tratarei, agora, da primeira das três grandes vertentes de ação: a continuidade dos Grupos de Estudos sobre Educação Sexual (GEES). Como foi dito, no início deste texto, o GEES é desenvolvido em encontros semanais, de quatro horas, de maio a fim de novembro, perfazendo um total de 22 encontros durante o ano. Com no máximo 20 integrantes em cada grupo, ele acontece no próprio campus universitário e forma, anualmente, uma média de 70 educadores. Nos primeiros anos de seu funcionamento, de 1995 a 1997, os GEES eram compostos, predominantemente, por professores de rede pública. Atualmente, são compostos, também, por profissionais da Saúde e da Assistência Social, embora aqueles continuem a ser maioria.

A partir de um estudo que culminou em minha tese de doutorado (FIGUEIRÓ, 2001), constatei que, embora o GEES seja importante e alcance os objetivos propostos, ele é insuficiente, pois, na fase em que os educadores formados vão desenvolver seus programas de Educação Sexual, surgem dificuldades e, por isso, é importante poder contar com a assessoria de especialistas. Desta forma, foi criado o Mutirão Orientador (M.O.) - segunda vertente das ações contra homofobia - no qual, em pequenos grupos, de dois a seis integrantes, no máximo, as pessoas que já foram integrantes do GEES têm assessoria dos 
psicólogos, que, como disse acima, recebem bolsa para esta atuação. Para isto, os integrantes dirigem-se até à universidade, uma vez por semana, discutem seus planejamentos, os resultados alcançados, as dificuldades e, sobretudo, continuam tendo orientaçōes para prosseguir em seus estudos sobre a sexualidade, com ênfase especial no tema da diversidade sexual, a fim de que este conteúdo seja priorizado em seu trabalho junto aos seus alunos.

Como ficou elucidado pelo referencial teórico, tanto o GEES, como o M.O., são trabalhos de formação continuada, desenvolvidos dentro do modelo reflexivo de formação, condizente com o pensamento de Schön (1997) e Perrenoud (1999), o qual valoriza a prática dos professores como embasamento para o processo formativo.

Quanto à terceira vertente de ações do projeto - organização de eventos ${ }^{2}$, na Universidade -, têm sido realizadas conferências, mesas-redondas e simpósio, com a participação de profissionais do Paraná, do Estado de São Paulo, do Rio Grande do Sul e de Brasília, que pesquisam sobre a temática e, sobretudo, são pessoas homossexuais. Estes eventos têm o propósito de complementar a formação vivenciada nos GEES e no M.O. e, também, de atingir outros profissionais e estudantes de graduação e de pós-graduação, a fim de ampliar o leque dos que possam participar do combate à homofobia e da promoção da cidadania homossexual. A vinda de profissionais militantes favoreceu a realização de uma série de entrevistas com os mesmos, na Rádio ${ }^{3}$ Universidade, da UEL, as quais foram ao ar várias vezes, atingindo um público ainda maior.

Da mesma forma, o tema foi levado à rede televisiva, em várias emissoras da cidade de Londrina (rede Globo, SBT e CNT), ocasião em que, como coordenadora do projeto, fui convidada para falar sobre o mesmo, como também, sobre os eventos que aconteceram no ano de 2006 e 2007.

2 Os eventos realizados na UEL, no período de vigência do Projeto UEL/MEC/SECAD, foram os seguintes:

- II Encontro para Reflexões sobre Homossexualidade - março de 2006.

- Encontro com Toni Reis - agosto de 2006.

- Il Simpósio Paraná / São Paulo / Santa Catarina sobre Sexualidade e Educação Sexual setembro de 2006.

- III Encontro para Reflexões sobre Homossexualidade - abril de 2007.

3 A Rádio da UEL, além de muitas entrevistas, no ano de 2006, também no período em que aconteceu o "III Encontro para a Reflexão sobre "Homossexualidade" - 2007, em comemoração aos seus 30 anos, realizou uma série denominada: Educação Sexual: novos conceitos, velhos tabus", no qual o tema da diversidade sexual foi o predominante. Como parte desta série, educadores inscritos do projeto também participaram com seus depoimentos. Como parte desta série, foi apresentada entrevista com Beto de Jesus e o "Encontro com Luiz Mott", um programa de uma hora de duração. 
Também vale registrar o fato de que a experiência do Projeto/UEL: "Formação de Profissionais para a Educação Sexual, o Combateà Homofobia e a Promoção da Cidadania Homossexual”, por diversas vezes, foi apresentada (a convite) em eventos ${ }^{4}$ fora da universidade, tanto na cidade de Londrina, quanto fora do Estado do Paraná. Estas participações, sem dúvida, constituíram-se em momentos importantes para se expandir as reflexões sobre a diversidade sexual em variados espaços acadêmicos.

No que diz respeito às demais ações contra a homofobia, implementadas no ano de 2007, a primeira delas, a realização de oficinas, tem acontecido nas escolas cujos professores são vinculados ao GEES ou ao M.O. e são coordenadas pelos psicólogos que atuam como assessores. São realizados dois encontros de três horas cada, em duas semanas consecutivas, e consegue-se trabalhar as informações básicas sobre homossexualidade, sensibilizando os profissionais para o enfrentamento da violência homofóbica. Nestas oficinas, há um cuidado especial quanto à inserção da educação para o respeito à diversidade sexual, no contexto de formação moral, assim como, a todo tipo de diversidade, incluindo a racial, religiosa e outras, conforme orientação recebida do consultor do Projeto/UEL, Beto de Jesus, homossexual militante e residente em São Paulo.

Quanto à segunda nova ação inserida: a publicação de textos sobre a temática, uma delas já foi efetivada, com o livro "Homossexualidade e Educação Sexual: construindo o respeito à diversidade sexual” (FIGUEIRÓ, 2007). Nesta obra, docentes dos demais departamentos que integram o projeto têm textos publicados e, um dos capítulos é formado por textos dos profissionais homossexuais militantes que ministraram conferências nos eventos. Duas outras publicações estão sendo concluídas.

\section{Considerações finais}

O contato com profissionais da saúde, da educação e da assistência social tem mostrado que se os chamarmos para o enfrentamento e para a contribuição no sentido de eliminar a violência homofóbica, conseguiremos significativa adesão e poderemos ver, a médio e a longo prazo, os resultados deste tipo de formação. Envolvendo-se com questôes sociais, como é o caso do combate

4 Em Londrina, a título de exemplo, cita-se a participação da coordenadora e de uma das psicólogas bolsistas do MEC, no evento intitulado: "Dia da Polêmica - a homofobia e os intolerantes", da Faculdade Uninorte, em maio de 2007.

Fora do Estado do Paraná, cita-se a participação da coordenadora no I Encontro de Grupos de Pesquisas da UNESP sobre Estudo da Sexualidade, em abril de 2006, ministrando a conferência cujo título é o mesmo deste artigo. 
à homofobia, o profissional pode acabar vendo mais significado em seu trabalho, pois, de acordo com a perspectiva emancipatória da Educação Sexual, ensinamos nossos alunos para que possam viver bem a sua sexualidade e sejam cidadãos críticos e participantes da transformação social dos valores e normas ligadas às questôes sexuais. (GOLDBERG, 1988)

Uma das questões que chama a atenção para a reflexão final dos possíveis alcances deste trabalho de extensão éo fato de que, anteriormente à vinculação com o Programa Brasil sem Homofobia (BRASIL, 2004), não havia acontecido, na UEL, eventos ${ }^{5}$ que oportunizassem pensar sobre a diversidade sexual. Segundo consta em instrumentos de avaliação aplicados aos participantes, no ano de 2006 e 2007, é reconhecido o resultado positivo que se alcança com o contato que os mesmos têm com profissionais homossexuais militantes, como aconteceu, por exemplo, com a participação de Luiz Mott, Beto de Jesus e Toni Reis, entre outros.

Isto faz-nos pensar no papel da universidade em criar espaços para que se pense e debata temas como este, assim como, também, sobre o aborto, pois acredito que a maioria de nossas universidades tem preferido omitir-se em algumas questôes que podem gerar confronto com as lideranças religiosas, especialmente, a católica.

Em todo o texto, voltei-me para a homofobia que é direcionada aos alunos na escola, porém, é bom estarmos cientes de que esta "doença” pode ter outros alcances, muito além do que se supõe; é o que nos alerta Mott (1997, p.21), ao dizer que "Também no corpo docente dos colégios e até universidades, a discriminação anti-homossexual tem feito suas vítimas [...]”. Na seqüência de sua fala, o autor inclui-se como vítima de violência na Universidade Federal da Bahia, onde foi professor e cita alguns jornais brasileiros que, no início da década de 90, relatam caso de perseguições a professores homossexuais.

Considero que a eficácia dos projetos de capacitação/formação de profissionais da educação para a cidadania e diversidade sexual pode, seguramente, ser maior, caso estes estejam inseridos dentro de um processo amplo de formação do educador sexual, como é o caso do GEES, por exemplo, onde há espaço para se conscientizar e sensibilizar sobre o papel da escola na Educação Sexual de crianças e jovens, entre outros objetivos e, onde, sobretudo, há oportunidades para que o educador repense os seus valores, mitos, tabus e preconceitos sobre todas as questôes relacionadas, direta ou indiretamente, à sexualidade.

5 Como exceção, é válido citar que, em 1998, foi realizado o I Encontro para Reflexões sobre Homossexualidade, sob minha coordenação e responsabilidade por ministrar as conferências que envolveram o dia todo. 
Enfim, estudar sobre a diversidade sexual e o papel da escola para a superação da mesma será tanto mais eficaz quanto isto se der dentro do estudo sobre Educação Sexual, de forma ampla e aprofundada.

Finalmente, vejo que medidas políticas de programas como o Brasil sem Homofobia, juntamente com o suporte financeiro, advindo de órgãos públicos ligados à Educação, como, neste caso, o MEC/SECAD, são imprescindíveis para que se concretize açōes efetivas de lutas políticas contra a opressão e a violência e em busca da educação de cidadãos engajados social e politicamente.

\section{Referências bibliográficas}

ABRAMOVAY, M; CASTRO, M. G.; SILVA, L. B. Juventudes e sexualidade. Brasília: UNESCO Brasil, 2004.

ALARCÃO, I. Formação continuada como instrumento de profissionalização docente. In: VEIGA, I. P. A. Caminhos da profissionalização do magistério. Campinas: Papirus, 1998, p.99-122.

ASSASSINATOS de homossexuais no Brasil. Disponível em: http://www. ggb.org.br/assassinatos/2005.html. Acesso dia: 13 de agosto de 2007

BARBIERI, M. R.; CARVALHO, C. P. de; UHLE, Á. B. Formação continuada dos profissionais do ensino. Cadernos CEDES, Campinas, n.36, p.29-35, 1995.

BASSO, I. S. Significado e sentido do trabalho docente. Cadernos CEDES, Campinas, n.44, p.19-32, 1998.

BRASIL sem Homofobia: programa de combate à violência e à discriminação contra GLTB e de promoção da cidadania homossexual. 2.ed. Brasília: Câmara dos Deputados, Coordenação de Publicações, 2004.

CAETANO M.RV. Os gestos do silêncio para esconder as diferenças. 2005. Dissertação (Mestrado Educação) - Universidade Federal Fluminense, Niterói, 2005.

CELANI, M. A. A. A educação continuada do professor. Ciência e Cultura, v.2, n.40, p.158-163, fev. 1988.

FEIL, I.S. Um treinamento... ou um caminho rumo a uma verdadeira educação? Cadernos CEDES, São Paulo, n. 14, p.69 - 75, 1985.

FIGUEIRÓ, M.N.D. (Org.) Homossexualidade e Educação Sexual: construindo o respeito à diversidade. Londrina: UEL, 2007.

Formação de educadores sexuais: adiar não é mais possível. Londrina: EDUEL; Campinas: Mercado de Letras, 2006.

A formação de educadores sexuais: possibilidades e limites. 2001. Tese (Doutorado em Educação) - Universidade Estadual Paulista, Marília. 
GIDDENS, A. A transformação da intimidade: sexualidade, amor e erotismo nas sociedades modernas. São Paulo: Ed. Universidade Estadual Paulista, 1993.

GOLDBERG, M. A. A. Educação Sexual: uma proposta, um desafio. 4.ed. São Paulo: Cortez, 1988.

JUNQUEIRA, R. D. A promoção da cultura do reconhecimento da diversidade sexual e o combate à homofobia como política pública de educação. In: II SIMPÓSIO DE SEXUALIDADE E EDUCAÇÃO SEXUAL PARANÁ - SÃO PAULO - SANTA CATARINA, 2., 2006, Londrina. Anais... Londrina: UEL, 2006. p.1. CD-ROM.

KRAMER, S. Melhoria da qualidade do ensino: o desafio da formação de professores em serviço. Revista Brasileira de Estudos Pedagógicos, Brasília, v.70, n.165, p.189-207, maio/ago. 1989.

MOTT, L. Homofobia: A violação dos direitos humanos de gays, lésbicas \& travestis. Salvador: Grupo Gay da Bahia, 1997.

NÓVOA, A. Formação de professores e profissão docente. In:

(Org.). Os professores e a sua formação. 3.ed. Lisboa: Dom Quixote, 1997, p.13-33.

PATTO, M. H. S. Apresentação. In: ANDALÓ, C. S. de A. Fala professora! São Paulo: Vozes, 1995. p.13-14.

PERES, W. S. Subjetividade das travestis brasileiras: da vulnerabilidade dos estigmas à construção da cidadania. 2005. Tese (Doutorado em Saúde Coletiva) - Instituto de Medicina Social da UERJ, Rio de Janeiro.

Violência, exclusão e sofrimento psíquico. In: RIOS, L.F. (Org.). Homossexualidade: produção cultural, cidadania e saúde. Rio de Janeiro: ABIA, 2004. p.116-122.

PERRENOUD, P. Formar professores em contextos sociais em mudança: prática reflexiva e participação crítica. Revista Brasileira de Educação, n.12, p.5-19, set./dez. 1999.

RAMIRES, L. Saúde dos homossexuais: a questão da resiliência. In: RIOS, L.F.. (Org.). Homossexualidade: produção cultural, cidadania e saúde. Rio de Janeiro: ABIA, 2004. p.161-162.

SCHÖN, D. A. Formar professores como profissionais reflexivos. In: NÓVOA, A. (Org.). Os professores e a sua formação. 3.ed. Lisboa: Dom Quixote, 1997, p.77-92.

TERTO Jr., V. Homossexuais soropositivos e soropositivos homossexuais: questôes da homossexualidade masculina em tempo de AIDS. In: PARKER, R.; BARBOSA, R.M. (Org.). Sexualidades brasileiras. Rio de Janeiro: Relume Dumará: ABIA: IMS/UERJ, 1996. 